\title{
O USO DA MADEIRA NAS REDUÇÕES \\ JESUÍTICO-GUARANI DO RIO GRANDE DO SUL 2 - VERGA DA FRONTARIA DA IGREJA DE SÃO MIGUEL ARCANJO ${ }^{1}$
}

\author{
CRISTINA SCHULZE-HOFER ${ }^{2}$ JOSÉ NEWTON CARDOSO MARCHIORI ${ }^{3}$
}

\section{RESUMO}

A madeira da verga da frontaria da igreja de São Miguel Arcanjo foi anatomicamente identificada como ipêroxo, Tabebuia heptaphylla (Vell.) Toledo, espécie nativa de notável resistência físico-mecânica e alta durabilindade natural.

Palavras-chave: Tabebuia heptaphylla, Anatomia da Madeira, Missões Jesuíticas.

\section{SUMMARY}

[Utilization of Wood in the Jesuitic-Guarani Missions from Rio Grande do Sul state, Brazil.

2 - Frontispiece lintel of Saint Michel Anchangel church].

The lintel wood of Saint Michel Archangel frontispiece was anatomically identified as Tabebuia heptaphylla (Vell.) Toledo (Bignoniaceae), a species named "ipê-roxo" (purple ipe) in the region, notable for its strength and decay resistance.

Key words: Tabebuia heptaphylla, Wood Anatomy, Jesuitic Missions.

\section{INTRODUÇÃO}

A igreja de São Miguel Arcanjo, Patrimônio da Humanidade, ainda apresenta algumas peças de madeira na admirável cantaria de suas paredes. É o caso da verga da porta oeste da fachada, peça razoavelmente bem preservada e de identidade anatômica ainda desconhecida. Ao identificar a espécie botânica, o presente trabalho visa a contribuir para o conhecimento das madeiras e das técnicas construtivas utilizadas pelos jesuítas no século XVIII.

\section{MATERIAL E MÉTODOS}

O material estudado consiste de uma amostra de madeira, retirada da verga da frontaria da igreja de São Miguel Arcanjo (Figura 1 A,B), município de São Miguel das Missões, Rio Grande do Sul. Coletada em junho de 2005, a amostra foi registrada em fichário, fotografada, acondicionada em envelope com identificação
(Figura 1 C,D) e depositada no Laboratório de Anatomia da Madeira do Instituto Nacional de Pesquisas da Madeira, em Lohbrügge-Hamburgo (Alemanha), onde foram realizados os trabalhos de microtécnica e fotomicrografia.

Da amostra de madeira foram preparados corpos-de-prova, orientados para a obtenção de cortes anatômicos nos planos transversal, longitudinal radial e longitudinal tangencial. Os corpos-de-prova foram fervidos em água até a expulsão completa do ar, e seccionados em micrótomo de deslizamento, modelo American Optical, com espessura nominal de corte de 20 $\mu \mathrm{m}$. Tendo em vista a boa conservação do tecido lenhoso, não foi preciso incluir, previamente, os corpos-de-prova em polietilenoglicol (PEG 2000). Também não se usou técnica de coloração nos cortes anatômicos; no caso dos radiais, parte deles foi tratado com hipoclorito de sódio, com vistas a salientar a presença de cristais de

Recebido em 10-8-2008 e aceito para publicação em 5-9-2008.

Arquiteta, Dra., IPHAN - Instituto do Patrimônio Histórico e Artístico Nacional. schulze-hofer@gmx.de

${ }^{3}$ Engenheiro Florestal, Dr., bolsista de Produtividade em Pesquisa do CNPq, Professor Titular do Departamento de Ciências Florestais, Universidade Federal de Santa Maria, CEP 97105-900, Santa Maria, (RS). balduinia@ mail.ufsm.br 

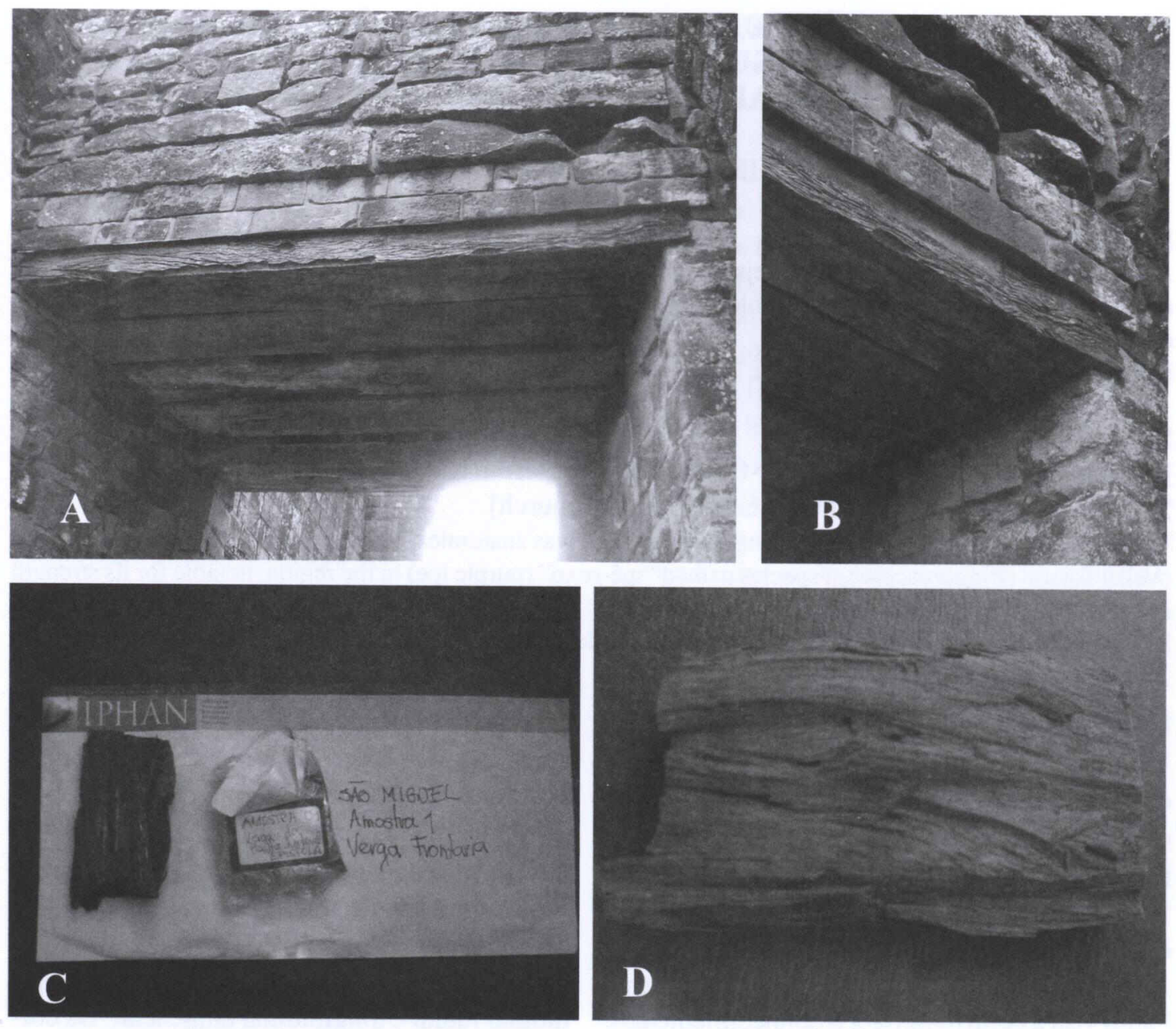

FIGURA 1 - A, B - Vistas da verga da frontaria da igreja de São Miguel Arcanjo. C - Acondicionamento da amostra de madeira. D - Registro fotográfico da amostra coletada.

sílica e oxalato de cálcio. As fotomicrografias da Figura 2 foram tomadas com câmera Olympus AX, com diferentes aumentos.

\section{DESCRIÇÃO ANATÔMICA}

Anéis de crescimento não visíveis no material examinado (Figura 2A). Madeira de porosidade difusa (Figura 2A), com poros muito numerosos, solitários, de forma redonda ou oval (Figura 2A,B) e em múltiplos radiais de 2-3 (Figura $2 \mathrm{~A}$ ), raro 4 poros. Elementos vasculares retilíneos (Figura 2C,E,F), com placas de perfuração simples e pontoações intervasculares al- ternas, não ornamentadas, de 12 a $14 \mu \mathrm{m}$ de diâmetro, com aréola arredondada e abertura lenticular inclusa (Figura 2F). Nos elementos vasculares, cabe salientar a ausência de espessamentos espiralados e a presença de abundante conteúdo amarelo (Figura 2C). Parênquima axial vasicêntrico incompleto, tendente a confluente, sem formar, todavia, faixas concêntricas (Figura 2A,B); séries parenquimáticas estratificadas em plano tangencial, geralmente com duas células por série. Raios homogêneos, com freqüência de 5-10/mm (Figura 2E), com- 

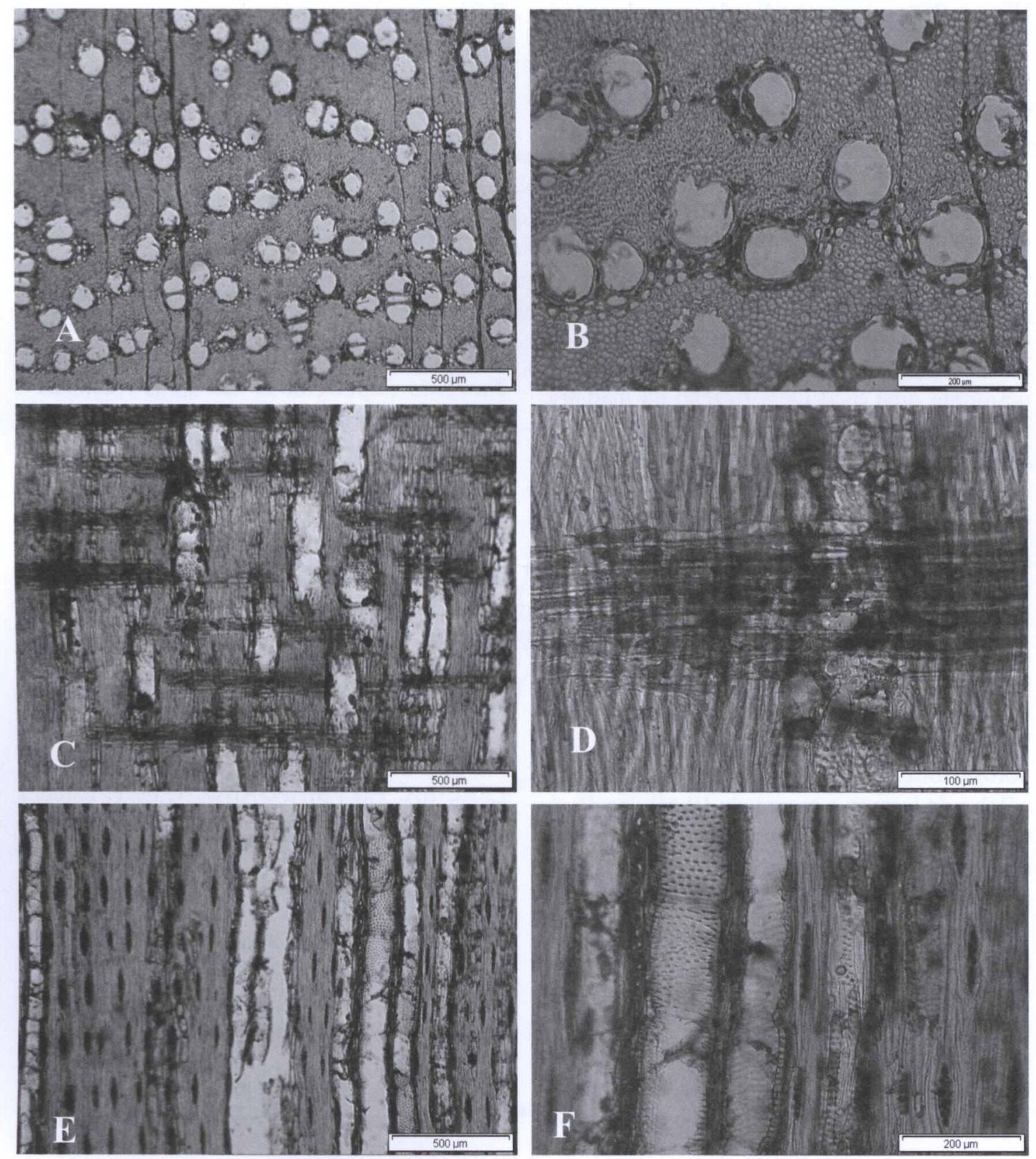

FIGURA 2 - Fotomicrografias da estrutura anatômica da madeira. A - Seção transversal, mostrando vasos muito numerosos, arredondados ou ovais, solitários e em múltiplos radiais de 2-3 poros, além de fibras de paredes muito espessas e parênquima vasicêntrico incompleto, tendente a confluente. B - Mesmos detalhes da foto anterior, com maior aumento. C - Seção longitudinal radial, salientando vasos retilíneos com abundante conteúdo amarelado (seta), raios homogêneos e fibras de paredes muito espessas. D - Detalhe de corte radial, mostrando abundante conteúdo em células procumbentes de raio e parênquima axial, além de fibras libriformes de paredes muito espessas. E - Seção longitudinal tangencial, destacando a estratificação completa, vasos retilíneos e raios finos. F - Detalhe de corte tangencial, mostrando raios bi e trisseriados, com menos de 10 células de altura, e pontoações intervasculares alternas, de 12-14 $\mu \mathrm{m}$ de diâmetro. 
postos inteiramente de células procumbentes (Figura 2D); raios estratificados, em plano longitudinal tangencial, com menos de 10 células de altura e geralmente trisseriados, menos comumente uni e multissseriados (Figura 2E,F). Fibras de paredes espessas a muito espessas (Figura 2B), do tipo libriforme (Figura 2D,F). Madeira de estratificação completa, incluindo elementos vasculares, parênquima axial, raios e fibras (Figura 2E, F).

\section{ANÁLISE DA ESTRUTURA ANATÔMICA}

Os detalhes anatômicos acima relacionados permitem uma fácil identificação da madeira. Mediante chave dicotômica para espécies com estrutura estratificada (Record 1943), chega-se, sem tropeços, à família Bignoniaceae, pelas pontoações não ornamentadas, pelos raios relativamente estreitos e baixos, pela porosidade difusa e pelos vasos desprovidos de espessamentos espiralados.

Em chave dicotômica para os grupos genéricos da mesma família, conclui-se que o material insere-se no "grupo Lapacho" do gênero Tabebuia (Record \& Hess, 1940), devido à porosidade difusa, aos raios com 3-4 (raro mais) células de largura e menos de 10 células de altura, ao parênquima escassamente vasicêntrico, aliforme até confluente, e à abundância de conteúdo amarelado nos vasos.

Com numerosas espécies e ampla distribuição geográfica, o "grupo Lapacho" distingue-se das demais seções de Tabebuia pela madeira castanho-esverdeada e de alta densidade, além da presença abundante de depósitos amarelados (lapachol) nos vasos do cerne (Record \& Hess, 1943). Por todos estes aspectos, não restam dúvi- das sobre a inclusão do material em estudo no referido grupo infragenérico.

O material examinado, por sua vez, assemelha-se, anatomicamente, ao descrito por Mainieri \& Chimelo (1989) para Tabebuia impetiginosa (Mart.) Standl., do mesmo "grupo Lapacho". Ao contrário dessa espécie, o material examinado distingue-se pelo parênquima menos abundante, não formando faixas de 2-7 células de largura. Sob o ponto de vista fitogeográfico, estas duas espécies afins apresentam distribuição alopátrica, ocorrendo Tabebuia hepthaphylla em florestas úmidas de terras baixas, e Tabebuia impetiginosa em áreas rochosas e secas (Pereira \& Mansano, 2008).

A comparação do material em estudo com lâminas de Tabebuia heptaphylla da coleção do Departamento de Ciências Florestais da Universidade Federal de Santa Maria, confirma a identificação. Única espécie de ipê-roxo na flora sul-rio-grandense, resta agregar que a madeira de Tabebuia heptaphylla (Vell.) Toledo é de notável resistência, inclusive sob o ponto de vista da biodeterioração.

\section{LITERATURACITADA}

PEREIRA, P.H., MANSANO, V. de F. Estudos taxonômicos da tribo Tecomeae (Bignoniaceae) no Parque Nacional do Itatiaia, Brasil. Rodriguésia, Rio de Janeiro, v. 59, n. 2, p. 265289, 2008.

RECORD, S. J. Woods of storied structure. Tropical Woods, n. 76, p. 32-47, 1943.

RECORD, S.J., HESS, R.W. American timbers of the family Bignoniaceae. Tropical Woods, n. 63, p. 938, 1940 .

RECORD, S.J., HESS, R.W. Timbers of the New World. New Haven: Yale University Press, 1943. 640 p. 